\title{
Connecting Older Veterans with Mental Health Mobile Apps: a Survey of Provider and Staff Use of Apps and Patient Education Materials
}

\author{
Christine E. Gould ${ }^{1,2}$ (D) Priyanka S. Mehta ${ }^{1} \cdot$ Chalise Carlson $^{1} \cdot$ Jason R. Anderson ${ }^{3} \cdot$ Ana Jessica Alfaro $^{1}$. \\ Erin Y. Sakai ${ }^{3}$
}

Received: 28 June 2021 / Revised: 9 November 2021 / Accepted: 13 November 2021 / Published online: 23 November 2021

This is a U.S. government work and not under copyright protection in the U.S.; foreign copyright protection may apply 2021

Mental health apps provide patients with psychoeducation, self-assessment, and tools to manage mental health symptoms such as anxiety, depressive, and posttraumatic stress symptoms. The US Department of Veterans Affairs (VA) and Department of Defense have developed mental health apps (e.g., PTSD Coach, Mindfulness Coach) which do not collect or share identifiable data (Gould et al., 2019; Owen et al., 2018) and are freely available to the general public. However, successful implementation of these mental health apps requires provider support and careful attention to patientlevel barriers to technology use (Connolly et al., 2021).

Surveys of VA mental and behavioral health providers demonstrate favorable perceptions of apps and ongoing use of apps with patients. In one survey (Miller et al., 2019), 80\% of providers reported using apps with patients, yet many identified several barriers to using apps including logistical challenges (e.g., finding time to help patients download apps) and patientfacing challenges (e.g., smartphone affordability, patient preference, comfort with apps). Reger et al. (2017) found that providers reported barriers to using apps as an adjunct to psychotherapy with patients who had low technology literacy and were less comfortable with their mobile device. These patientfacing challenges highlight the need to support providers in promoting digital literacy for their patients.

When considering implementation of apps within the Veterans Health Administration (VHA), it is particularly important to consider digital literacy as $46.2 \%$ of all military veterans in the USA are aged 65 years or older (National

Christine E. Gould

christine.gould@va.gov

1 Geriatric Research Education and Clinical Center, GRECC (182B), VA Palo Alto Health Care System, 3801 Miranda Ave, Palo Alto, CA 94304, USA

2 Department of Psychiatry \& Behavioral Sciences, Stanford University School of Medicine, Palo Alto, CA, USA

3 Psychology Service, VA Palo Alto Health Care System, Palo Alto, CA, USA
Center for Veterans Analysis \& Statistics, 2020). Older veterans are more likely to face challenges to effectively using mobile devices without assistance compared with younger veterans (Gould \& Hantke, 2020; Slightam et al., 2020). Of veteran mobile device owners surveyed, few (10-11\%) had ever downloaded health apps despite many having reported interest in these apps (Gould et al., 2020a; Lipschitz et al., 2019). Furthermore, many older veterans may present with complex mental health issues encompassing physical, mental, and cognitive challenges (Karel et al., 2020). These complex problems facing older patients combined with lower technology comfort or knowledge (Reger et al., 2021) may result in providers not discussing apps with older veterans.

To address this potential implementation gap with regard to digital literacy and awareness of VA mental health apps, we developed patient education materials aimed toward older (or novice) users of mobile devices (Gould et al., 2020b). The materials, designed using an iterative User-Centered Design approach, teach the basics of mobile devices, explain how to download an app, and provide step-by-step guides to three VA mental health self-management apps (PTSD Coach, Mindfulness Coach, Mood Coach). The materials aim to facilitate ease of use, highlight perceived usefulness of the apps, mitigate gerontechnology anxiety, and provide information about sensory/health factors specific to older adults (Chen \& Chan, 2014; Davis et al., 1989). As part of the dissemination of these materials, we conducted surveys with staff and providers to (1) ascertain perceptions of using mental health apps with older veterans and (2) to examine satisfaction with patient education materials and potential barriers to use.

\section{Methods}

\section{Participants}

Participants were respondents requesting mobile app patient education materials. Materials have been disseminated 
throughout the VHA via webinars, newsletter articles, email announcements, and word-of-mouth. The Stanford University IRB reviewed this project and determined that it was not human subjects research.

\section{Measures and Procedures}

This investigation describes the pre-distribution assessment and anonymous postevaluation of patient education materials. Available materials included individual pamphlets and "starter kits" for Apple/iOS and/or Android devices. Starter kits included the following individual pamphlets: "How to Download Apps," "Mobile Device Information," and "Stepby-Step App Guides" (see Fig. 1). Step-by-Step App Guides were developed for PTSD Coach, Mindfulness Coach, and Mood Coach (see Gould et al., 2020b). Due to Mood Coach only being available on iOS devices, a limited number were printed and disseminated. Mood Coach will be retired and replaced with a new VA app focused on depressive symptoms. All materials were shipped within approximately 2 weeks.

On an online request form, four questions were addressed: frequency of app recommendation or use in clinical practice, expected advantages of app use, comfort with recommending and using apps with older veterans, and requestor's discipline. Four months after the material distribution, a follow-up survey was sent to requestors to ascertain frequency of app use in practice, comfort in recommending apps, extent that materials improved comfort with recommending apps, and perceived barriers to material use.

\section{Data Analysis}

Frequencies and descriptive statistics summarized the quantitative data. Two authors (CC, PM) coded open-ended responses independently. Codes were refined by all authors; final coding was decided by consensus when needed. Categories were reviewed and thematic analysis ensued with themes refined during team meetings (Guest et al., 2012).

\section{Results}

Between December 2018 and August 2020, we received 96 requests (from 90 unique individuals) across 36 states with 3032 starter kits and 4043 individual pamphlets distributed. The most requested pamphlets were "How to Download an App" and the "Mobile Device Information" pamphlets. Requestors comprised the following disciplines: psychology $(n=45,46.9 \%)$, social work $(n=19,19.8 \%)$, MyHealtheVet coordinator/telehealth ( $n=11,11.5 \%)$, other health care providers $(n=6,6.3 \%)$, nursing $(n=5,5.2 \%)$, other mental health $(n=5,5.2 \%)$ or administrative $(n=3,3.1 \%)$. Most $(98 \%)$ were from a VHA site or Vet Center and reported low comfort (68.5\%; "not at all" to "slightly comfortable") with recommending apps (see Table 1).

Baseline open-ended responses highlighted several use cases for apps across the mental health treatment continuum. These use cases included older patients using apps to self-manage symptoms, receive support at home, and integrate information and skills learned from psychotherapy into daily life. Respondents identified numerous potential advantages that the apps would provide, which we summarized into four categories: (1) access to information and coping skills; (2) general psychoeducational support and guidance; (3) self-management of symptoms; and (4) reinforcing specific therapy skills (see Table 2). The advantages described emphasized that the VA mental health apps are free, readily accessible, and contain tools to monitor symptoms, consolidate skills learned in psychotherapeutic interactions, and to generally support mental health.

Follow-up surveys (see Table 1) were completed by 26 individuals (28.9\% response rate). Many respondents (69.2\%)
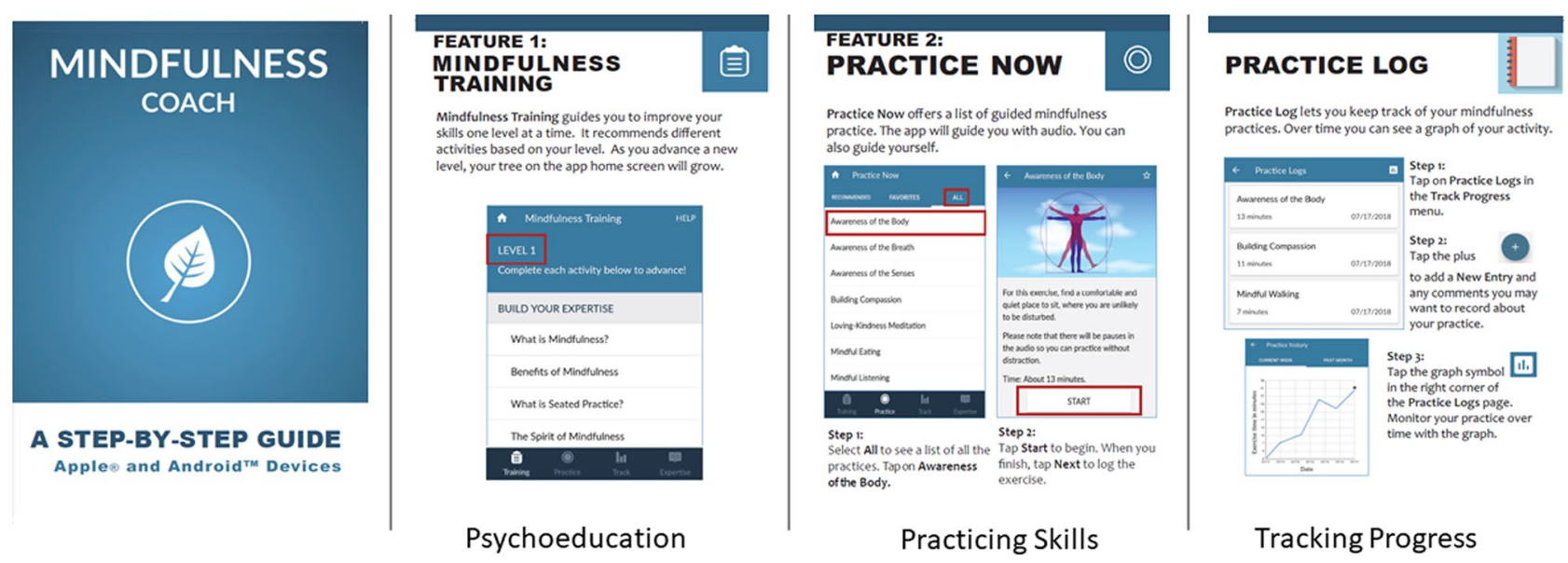

Fig. 1 Sample education materials for Mindfulness Coach 
Table 1 Baseline request and follow-up survey results

\begin{tabular}{|c|c|c|c|c|c|}
\hline Item & $N(\%)$ & & & & \\
\hline \multicolumn{6}{|l|}{ Baseline survey $(N=96)$} \\
\hline $\begin{array}{l}\text { How often do you recommend } \\
\text { mobile apps }{ }^{\mathrm{a}}\end{array}$ & $\begin{array}{l}13(14.6 \%) \text { never } \\
\text { (0 times) }\end{array}$ & $\begin{array}{l}29(32.6 \%) \text { once } \\
\text { every few } \\
\text { months } \\
(<1 / \text { month })\end{array}$ & $\begin{array}{l}47 \text { (52.8\%) monthly } \\
\text { (1-4/months) }\end{array}$ & $\begin{array}{l}0 \text { (0.0\%) weekly } \\
\text { (> 5/months) }\end{array}$ & \\
\hline $\begin{array}{l}\text { How comfortable are you in rec- } \\
\text { ommending or using mobile apps } \\
\text { with older veterans? }\end{array}$ & $26(29.2 \%)$ not at all & $35(39.3 \%)$ slightly & $26(29.2 \%)$ moderately & $4(4.5 \%)$ very & $1(1.1 \%)$ extremely \\
\hline \multicolumn{6}{|l|}{ 4-month follow-up survey $(N=26)$} \\
\hline $\begin{array}{l}\text { How often do you use mobile apps } \\
\text { in your practice? }\end{array}$ & $0(0.0 \%)$ never & $1(4.0 \%)$ rarely & $14(56.0 \%)$ sometimes & $7(28.0 \%)$ usually & $3(12.0 \%)$ always \\
\hline $\begin{array}{l}\text { How comfortable are you in } \\
\text { recommending apps to older } \\
\text { veterans? }\end{array}$ & $0(0.0 \%)$ not at all & $2(7.7 \%)$ slightly & $8(30.8 \%)$ moderately & $8(30.8 \%)$ very & $8(30.8 \%)$ extremely \\
\hline $\begin{array}{l}\text { How often use Geri-Mobile } \\
\text { materials? }\end{array}$ & $1(3.8 \%)$ never & $7(26.9 \%)$ rarely & $13(50.0 \%)$ sometimes & $4(15.4 \%)$ usually & $1(3.8 \%)$ always \\
\hline $\begin{array}{l}\text { Did materials improve your com- } \\
\text { fort with recommending mobile } \\
\text { apps? }\end{array}$ & $2(7.2 \%)$ no change & $2(7.7 \%)$ slightly & $14(53.8 \%)$ moderately & $4(15.4 \%)$ very & $4(15.4 \%)$ extremely \\
\hline
\end{tabular}

Due to some missing items, the total sample size varied for some questions: ${ }^{\mathrm{a}} N=89,{ }^{\mathrm{b}} N=92,{ }^{\mathrm{c}} N=25$

reported using the materials "sometimes" or "more frequently" with their patients. Most $(84.6 \%)$ indicated that the materials improved their comfort in recommending apps; only $15.4 \%$ reported slight or no change in comfort. Thematic analysis revealed that the perceived advantages to the materials primarily were related to the need to educate veterans about mobile technology, smartphones, and the apps themselves (see Table 2). Respondents' feedback exemplified the challenges that novice users face in using smartphones and other technology (computers, tablets), understanding how to download apps, and knowing how to use a specific app and its features. Respondents highlighted that the materials address these challenges through providing "a useful introduction to smartphones;" "scaffolding around downloading an app, finding it again on their phone;" and "learning how to engage with the applications."

Few $(n=4)$ noted barriers, including mailing limitations during the COVID-19 pandemic, older patients being "adverse to smartphones," lacking Wi-Fi in the office, or challenges with specific VA/DoD apps that require enhanced login credentials. Notably, enhanced login credentials are needed for apps that are connected to the electronic health record, but not for the mental health apps that are highlighted in the materials discussed herein.

\section{Discussion}

This investigation identified several areas in which mental health apps can help older patients, including increasing access to mental health resources, provision of psychoeducational support and guidance, self-management of symptoms, and reinforcement of therapy skills. Findings suggested that the educational materials may have contributed to providers' comfort with recommending apps. This report of increased comfort was likely due to providers' perception that the materials would successfully introduce older veterans to smartphone features and facilitate engagement with apps. Low patient comfort with apps, as well as having to spend time helping patients download them, may make providers less likely to recommend mental health apps to patients (Miller et al., 2019). Such barriers are problematic, as numerous apps may improve mental health (Wang et al., 2018). Taken together, these findings suggest that providers believe educational materials could increase novice users' comfort with mobile devices and help them download apps independently.

Barriers to implementing the patient education materials include the reliance on physical materials. To address this barrier, we created adapted electronic handouts describing the basics of mobile devices and downloading apps, which are available on the public-facing VA website (https://www. va.gov/GERIATRICS/docs/Mobile_Device_Info_Apple. pdf and https://www.va.gov/GERIATRICS/docs/Mobile_ Device_Info_Android.pdf). Future ways of addressing dissemination of materials to support patients' digital literacy include having a self-service "virtual resource room" or the inclusion of materials in existing training programs that teach providers how to effectively implement apps into care (e.g., Armstrong, 2019; Armstrong et al., 2021). Future directions for implementation of mental health apps should 
Table 2 Advantages of VA mental health mobile apps and patient education materials

\begin{tabular}{|c|c|}
\hline Advantages & Quotes \\
\hline \multicolumn{2}{|l|}{ VA mental health apps } \\
\hline Access to information and coping skills & $\begin{array}{l}\text { "Apps are available } 24 / 7 \text { and are usually on/with the person" } \\
\text { "Ready access to needed and relevant information, virtual coaching through } \\
\text { skills and techniques, no handouts to lose" } \\
\text { "These apps will improve access to intervention, particularly for our rural } \\
\text { veterans" } \\
\text { "No copay" }\end{array}$ \\
\hline Psychoeducational support and guidance & $\begin{array}{l}\text { "Want to use the safety plan app" } \\
\text { "Additional tools for treatment beyond hospitalization" } \\
\text { "Continued tools of support" } \\
\text { "The ability for veterans to have clear instructions and guidance at home." }\end{array}$ \\
\hline Self-management of symptoms & $\begin{array}{l}\text { "Apps are the perfect tool to engage and empower the patient in their health } \\
\text { and health outcomes" } \\
\text { "Self-monitoring that will facilitate a more streamline[d], self-reliant experi- } \\
\text { ence" } \\
\text { "Providing a greater sense of independent mastery" }\end{array}$ \\
\hline Reinforcing therapy skills and extend work outside of sessions & $\begin{array}{l}\text { "In between appointment practice and skill building, tracking progress, } \\
\text { build resiliency" } \\
\text { "Better understanding of psychoeducation...we use the apps in session so it } \\
\text { makes it more likely/easier to use outside of session" } \\
\text { "Increased likelihood of compliance with mindfulness homework" } \\
\text { "Being able to practice therapy skills outside of session while being } \\
\text { 'guided"" }\end{array}$ \\
\hline Need for education and support to use apps and devices & $\begin{array}{l}\text { "The brochures are helpful for vets that don't understand how to download } \\
\text { apps." } \\
\text { "I have many patients who struggle with using smart phone devices AND } \\
\text { other technology (computers, tablets)" }\end{array}$ \\
\hline \multicolumn{2}{|l|}{ Patient education materials } \\
\hline Provide overview of app use and address patients' knowledge gaps & $\begin{array}{l}\text { "The materials provide a useful introduction to smartphones, particularly for } \\
\text { those who are new to mobile technology." } \\
\text { "I use the materials often when I feel the veterans could benefit from added } \\
\text { support or education. Many have found the resources very helpful in learn- } \\
\text { ing how to engage with the applications." }\end{array}$ \\
\hline Distribute materials to other providers and clinics & $\begin{array}{l}\text { "Our site has an older veteran population who may benefit from this } \\
\text { information. Will provide this information to our clinicians to provide to } \\
\text { patients." }\end{array}$ \\
\hline Overall positive impression of materials & $\begin{array}{l}\text { "I think they are great and look forward to adding them to our educational } \\
\text { materials as we currently work to create a virtual resource room." }\end{array}$ \\
\hline
\end{tabular}

include disseminating educational materials to non-mental health providers (Connolly et al., 2021). Approximately $26 \%$ of our initial respondents were not mental health providers. Given older adults are particularly receptive to mental health care in primary care settings (Unutzer et al., 2002), dissemination of materials in those settings may help nonmental health providers feel more comfortable introducing mental health apps to older veterans. Future directions also should examine human support approaches including peers (Fortuna et al., 2019; Montena et al., 2021), digital health navigators in clinics (Wisniewski \& Torous, 2020), or technology training and classes through senior centers or libraries. Providing human support to novice users may be critical to their adoption of these technologies.

Several limitations should be noted. Respondents were likely interested in supporting older veterans' mobile app use, given that they requested materials. Our findings may not generalize to individuals who did not request the materials or to providers outside of the VA health care system. We did not collect information about providers' demographics, comfort with technology, or experience teaching technology, factors that could have influenced their responses. Baseline and follow-up surveys were not linked, which prevents comparison of respondents and non-respondents to the follow-up surveys. It is possible that providers with greater technological comfort and experience were more likely to complete a follow-up survey. Additionally, it is possible that those who did not complete the follow-up survey may have had more neutral or less favorable perceptions of the educational materials compared with respondents. Furthermore, a small number of providers responded to the follow-up survey.

In conclusion, our preliminary findings indicate that patient education materials, including technology basics and specific 
app instructions, improve providers' comfort with recommending mental health apps to older patients, thereby increasing intervention options. Thus, ensuring providers and staff have access to patient education materials for smartphone and mental health mobile app use may be critical for implementation of mental health apps into ongoing patient care.

Acknowledgements Ashley Scales, $\mathrm{PhD}, \mathrm{MPH}$, contributed to the initial design of the survey and assisted with distributing the materials. Views expressed in this article are those of the authors and not necessarily those of the Department of Veterans Affairs or the Federal Government.

Author Contribution Christine Gould: funding acquisition, writing, conceptualization, data analysis, supervision, validation, methodology. Priyanka Mehta: project administration, investigation, data curation, data analysis. Chalise Carlson: project administration, data curation, data analysis. Jason Anderson: validation, writing, reviewing, and editing. Ana Jessica Alfaro: validation, reviewing, and editing. Erin Sakai: conceptualization, validation, reviewing, and editing.

Funding Development and printing of the patient education materials was supported by 160 Funds from the United States (US) Department of Veterans Affairs, Geriatrics and Extended Care (Project Director: Gould). Dr. Gould is supported by a Career Development Award (IK2 RX001478; PI: Gould) from the US Department of Veterans Affairs Rehabilitation Research and Development Service.

Data and Material Availability Patient education materials are available upon request from the authors. A limited data set will be available upon reasonable request.

\section{Declarations}

Ethics Approval The Stanford University IRB reviewed this project and determined that it was not human subjects research.

Conflict of Interest The authors declare no competing interests.

\section{References}

Armstrong, C. M. (2019). Mobile health provider training: Results and lessons learned from year four of training on core competencies for mobile health in clinical care. Journal of Technology and Behavioral Science, 4, 86-92. https://doi.org/10.1007/ s41347-019-00089-8

Armstrong, C. M., McGee-Vincent, P., Juhasz, K., Owen, J., Avery, T., Jaworski, B., \& Hilty, D. M. (2021). VA Mobile Health Practice Guide (1st ed.). U.S. Department of Veterans Affairs.

Chen, K., \& Chan, A. H. S. (2014). Gerontechnology acceptance by elderly Hong Kong Chinese: A senior technology acceptance model (STAM). Ergonomics, 57, 635-652. https://doi.org/10. 1080/00140139.2014.895855

Connolly, S. L., Hogan, T. P., Shimada, S. L., \& Miller, C. J. (2021). Leveraging implementation science to understand factors influencing sustained use of mental health apps: A narrative review. Journal of Technology and Behavioral Science, 6, 184-196. https://doi.org/10.1007/s41347-020-00165-4

Davis, F. D., Bagozzi, R. P., \& Warshaw, P. R. (1989). User acceptance of computer technology: A comparison of two theoretical models. Management Science, 35, 982-1003. https://doi.org/10. 1287/mnsc.35.8.982

Fortuna, K. L., Brooks, J. M., Umucu, E., Walker, R., \& Chow, P. I. (2019). Peer support: A human factor to enhance engagement in digital health behavior change interventions. Journal of Technology and Behavioral Science, 4, 152-161. https://doi.org/10.1007/ s41347-019-00105-x

Gould, C. E., \& Hantke, N. C. (2020). Promoting technology and virtual visits to improve older adult mental health in the face of COVID-19. American Journal of Geriatric Psychiatry, 28, 889890. https://doi.org/10.1016/j.jagp.2020.05.011

Gould, C. E., Kok, B. C., Ma, V. K., Zapata, A. M. L., Owen, J. E., \& Kuhn, E. (2019). Veterans Affairs and the Department of Defense mental health apps: A systematic literature review. Psychological Services, 16, 196-207. https://doi.org/10.1037/ser0000289

Gould, C. E., Loup, J., Kuhn, E., Beaudreau, S. A., Ma, F., Goldstein, M. K., Wetherell, J. L., Zapata, A. M. L., Choe, P., \& O'Hara, R. (2020a). Technology use and preferences for mental health selfmanagement interventions among older veterans. International Journal of Geriatric Psychiatry, 35, 321-330. https://doi.org/10. 1002/gps.5252

Gould, C. E., Loup, J. R., Scales, A. N., Juang, C., Carlson, C., Ma, F., \& Sakai, E. Y. (2020b). Development and refinement of educational materials to help older veterans use VA mental health mobile apps. Professional Psychology: Research and Practice, 51, 414-423. https://doi.org/10.1037/pro0000354

Guest, G., MacQueen, K. M., \& Namey, E. E. (2012). Applied thematic analysis. Los Angeles, CA: SAGE.

Karel, M. J., Wray, L. O., Adler, G., Hannum, A. O., Luci, K., Brady, L. A., \& McGuire, M. H. (2020). Mental health needs of aging veterans: Recent evidence and clinical recommendations. Clinical Gerontologist. https://doi.org/10.1080/07317115.2020.1716910

Lipschitz, J., Miller, C. J., Hogan, T. P., Burdick, K. E., Lippin-Foster, R., Simon, S. R., \& Burgess, J. (2019). Adoption of mobile apps for depression and anxiety: Cross-sectional survey study on patient interest and barriers to engagement. JMIR Mental Health, 6(1), e11334. https://doi.org/10.2196/11334

Miller, K. E., Kuhn, E., Yu, J., Owen, J. E., Jaworski, B. K., Taylor, K., Blonigen, D. M., \& Possemato, K. (2019). Use and perceptions of mobile apps for patients among VA primary care mental and behavioral health providers. Professional Psychology: Research and Practice, 50, 204. https://doi.org/10.1037/pro0000229

Montena, A. L., Possemato, K., Kuhn, E., Carlson, E. B., McGovern, M., Smith, J., \& Blonigen, D. (2021). Barriers and facilitators to peer-supported implementation of mental health mobile applications with veterans in primary care. Journal of Technology in Behavioral Science. https://doi.org/10.1007/s41347-021-00198-3

National Center for Veterans Analysis and Statistics, Veteran Population. (2020). https://www.va.gov/vetdata/veteran_population.asp. Accessed 5 Feb 2021.

Owen, J. E., Kuhn, E., Jaworski, B. K., McGee-Vincent, P., Juhasz, K., Hoffman, J. E., \& Rosen, C. (2018). VA mobile apps for PTSD and related problems: Public health resources for veterans and those who care for them. The Journal of mHealth. https://doi.org/ 10.21037/mhealth.2018.05.07

Reger, G. M., Browne, K. C., Campellone, T. R., Simons, C., Kuhn, E., Fortney, J. C., Sayre, G. G., \& Reisinger, H. S. (2017). Barriers and facilitators to mobile application use during PTSD treatment: Clinician adoption of PE coach. Professional Psychology: Research and Practice, 48(6), 510-517. https://doi.org/10.1037/ pro0000153

Reger, G. M., Harned, M., Stevens, E. S., Porter, S., Nguyen, J., \& Norr, A. M. (2021). Mobile applications may be the future of veteran mental health support but do veterans know yet? A survey of app knowledge and use. Psychological Services. https://doi.org/ $10.1037 /$ ser0000562 
Slightam, C., Gregory, A. J., Hu, J., Jacobs, J., Gurmessa, T., Kimerling, R., Blonigen, D., \& Zulman, D. M. (2020). Patient perceptions of video visits using Veterans Affairs telehealth tablets: Survey study. Journal of Medical Internet Research, 22, e15682. https://doi.org/ $10.2196 / 15682$

Unutzer, J., Katon, W., Callahan, C. M., Williams, J. W. J., Hunkeler, E., Harpole, L., Hoffing, M., Della Penna, R. D., Noel, P. H., Lin, E. H. B., Arean, P. A., Hegel, M. T., Tang, L., Belin, T. R., Oishi, S., \& Langston, C. (2002). Collaborative care management of late-life depression in the primary care setting: A randomized controlled trial. JAMA, 288, 2836-2845. https://doi.org/10.1001/ jama.288.22.2836
Wang, K., Varma, D. S., \& Prosperi, M. (2018). A systematic review of the effectiveness of mobile apps for monitoring and management of mental health symptoms or disorders. Journal of Psychiatry Research, 107, 73-78. https://doi.org/10.1016/j.jpsychires.2018.10.006

Wisniewski, H., \& Torous, J. (2020). Digital navigators to implement smartphone and digital tools in care. Acta Psychiatrica Scandinavica, 141, 350-355. https://doi.org/10.1111/acps.13149

Publisher's Note Springer Nature remains neutral with regard to jurisdictional claims in published maps and institutional affiliations. 